\title{
Neurobiological Background of Affective Disorders
}

\author{
Peter Falkai, Berend Malchow and Andrea Schmitt
}

Additional information is available at the end of the chapter

http://dx.doi.org/10.5772/51801

\section{Introduction}

Affective disorders, including major depression, mania and bipolar disorder, represent a spectrum of severe psychiatric diseases reflecting a continuum of psychopathological symptoms. Starting in young adulthood and often leading to suicidal ideation, affective disorders are ranking among the most disabling diseases worldwide in terms of the WHO global burden of disease, are socio-economically relevant, severe and prevalent. These diseases lead to enormous social disabilities due to affective and cognitive symptoms [1]. Depression, for example, has a lifetime risk of about 20-25\% [2] and, besides suicide, a higher prevalence of the metabolic syndrome including coronary heart disease and diabetes increase mortality [3]. Bipolar disorder with manic episodes, in contrast, has a lifetime prevalence of about 1-5\% [4]. However, due to the occurrence of depressive symptoms, the disease may be misdiagnosed - Goldberg et al. [5] could show a hypo-manic or manic episode in $46 \%$ in patients with depression.

Despite tremendous efforts, the neurobiological background of affective disorders remains elusive, and due to lacking biomarkers an early diagnosis and reliable prognosis is difficult. Undisputed is a multifactorial etiology with genetic and psychosocial factors such as stress, emotional trauma and viral infections during the vulnerable episodes of brain development. They possibly interact in inducing disease symptoms. Beside neuroendocrinological factors, neurotransmitter disturbances and alterations of signal transduction constitute the basis of structural and functional alterations in neuronal circuits of the brain.

\section{Neuroimaging studies in affective diseases}

Since the description of the limbic "Papez-circuit of emotion" in the 1930s involving hippocampus, cingulated gyrus, anterior thalamus and hypothalamus, magnetic resonance 
imaging [6] studies in patients revealed volume deficits in regions relevant for emotion processing, be it amygdala, hippocampus, anterior cingulate gyrus, prefrontal, or orbitofrontal cortex as well as basal ganglia. In bipolar disorder, affective and psychotic symptoms are related to a dysfunction in the prefrontal-subcortical network interacting with limbic regions [7]. Meta-analyses in bipolar disorder indeed show gray matter reductions in the paralimbic regions anterior cingulate cortex and insula, partially overlapping with decreased volumes in schizophrenia and indicating a continuum of the neurobiological background of psychoses [8, 9]. Anterior cingulate dysfunction in bipolar disorder has been strengthened by functional MRI studies, which revealed functional attenuation in the anterior cingulated cortex in patients with bipolar disorder performing cognitive and emotional tasks $[10,11]$. Recent meta-analyses of fMRI studies in bipolar disorder show decreased activation of the inferior frontal cortex corresponding to frontal hypoactivity and overactivated hippocampus plus amygdala (limbic hyperactivity), which was consistent across emotional and cognitive tasks and related to the state of mania [12, 13]. Reduced fractional anisotropy nearby the parahippocampal gyrus and anterior cingulate cortex have been identified in diffusion-tensor imaging studies in bipolar disorder and speak for impaired limbic connectivity in neuronal networks [14]. With respect to amygdala size, decreased volumes have only been detected in younger patients and a respective correlation between volume and age has been reported $[15,16]$. Contrastingly, schizophrenia patients showed larger ventricles and smaller amygdala volumes compared to bipolar disorder, pointing to a continuum of neurobiological alterations [8].

Compared to patients with bipolar disorder, those with major depressive disorders present decreased rates of white matter hyperintensity, smaller hippocampal and basal ganglia volumes and a decreased corpus callosum area [17, 18]. Along with increased lateral ventricles, smaller volumes of the basal ganglia, hippocampus, thalamus, frontal lobe, orbitofrontal gyrus and gyrus rectus have been detected in major depression [19]. This especially pertained patients during depressive episodes with smaller hippocampal volumes compared to remittend patients [18]. Reduced hippocampal volumes have consistently been reported in patients with major depression and are prominent in patients with recurrent and chronic depression [20]. Shape analysis revealed deformations in the subiculum, CA1 and CA2-3 subfields in the tail of the right hippocampus of patients with first episode of depression [21]. The presence of alterations in first-episode depression is consistent with a neurodevelopmental hypothesis of early stress experience, especially since this region plays a major role in inhibiting stress response [22], providing inhibitory feedback to the hypothalamic-pituitary-adrenal (HPA) axis [23].

\section{Synaptic plasticity and stress mediation}

Post-mortem investigations reveal reduced density and size of interneurons in cornu ammonis (CA) 2/3 subfield of the hippocampus in bipolar disorder [24]. In the hippocampal subiculum, a decreased density of neuronal dendrites leading to disturbances of microconnectivity and probably representing the basis of the reported volume deficit in 
bipolar patients has been found [25]. However, the finding of decreased neuropil (dendrites and axons) seems not to be specific for bipolar disorder, as it has also been reported in all hippocampal subfields of patients with major depression showing increased density of neurons and glia cells as a sign of increased packing of the cells. Additionally, in line with the hypothesis of a degenerative process, soma size of pyramidal neurons was decreased [26]. In the prefrontal cortex of patients with major depression, a decrease in cortical thickness goes along with lower densities of neurons and glia cells [27]. In the anterior cingulate cortex, in familial depression and bipolar disorder, decreased glia number has been detected [28]. In both regions, decrease of glia density and neuronal size has been reported [29]. Decreased glia density has also been found in the amygdala of patients with major depression [30]. In animal studies again, chronic stress or repeated administration of glucocorticoids interestingly results in degeneration of hippocampal neurons with decreased soma size and atrophy of dendrites $[31,32]$. Stress possibly also influences synaptic plasticity in the prefrontal cortex [33]. Thus the volume loss in brain regions like the hippocampus reported in affective disorders may indeed be mediated by stress-induced glucocorticoid neurotoxicity [34, 35].

Division and differentiation of stem cells to neurons and their migration to the granule cell layer has been demonstrated in the hippocampal dentate gyrus of both humans and adult rodents [36]. Some factors influence this neurogenesis: While blockade of the glutamatergic $\mathrm{N}$-methyl-D-aspartate (NMDA) receptor and adrenalectomy results in increased production of granule neurons, adrenal steroids and NMDA receptor activation diminished neurogenesis [37]. Acute, chronic or prenatal stress, all of them implicated in the pathophysiology of depression [38], have been shown to inhibit proliferation of subgranular neurons [39-42]. Because both, circulating adrenal steroids and glutamate-induced excitatory input to the hippocampus, are enhanced by stress [43, 44], the influence of stressful events on cell proliferation and survival of newly generated neurons may be mediated by these mechanisms [40, 45]. In an animal model of learned helplessness, inescapable stress is leading to downregulation of neurogenesis [46]. Accordingly, antidepressants are known to induce cell proliferation and neurogenesis [46-49].

\section{Neurotrophins and the HPA axis}

Neurotrophic factors, particulary Brain-Derived Neurotrophic Factor (BDNF) are expressed in the hippocampus and cortex and are involved in neurogenesis and synaptic plasticity such as promotion of survival and differentiation as well as branching of axons and dendrites [50]. In patients with bipolar disorder, reduced hippocampal expression of BDNF has been reported [51] while antidepressants reversed this effect [52]. In blood of depressed patients, including patients with bipolar disorder, BDNF levels have been found to be decreased and correlated to higher depression evaluation scores [53, 54]. Post-mortem studies of the hippocampus in major depression revealed a reduced BDNF immunhistochemistry [51].

To date, beside a genetic vulnerability, stress is widely accepted as risk factor for depression. In animal models, acute or chronic stress decreased BDNF levels in the hippocampus 
inclusive the dentate gyrus [52]. Along with this hypothesis, stress is known to reduce the branching of hippocampal dendrites [55]. It additionally increases plasma and adrenal corticosterone levels and application of this hormone induces reduced hippocampal BDNF levels, mimicking stress reaction [52]. The major stress system of the body is the HPA axis, a neuroendocrine system involved in the production of the stress hormone cortisol by adrenal glands. In more than $50 \%$ of patients with major depression, a dysfunction of the HPA axis with increased basal cortisol levels and dexamethasone non-suppression of cortisol was detected, suggesting abnormal negative feedback system of the HPA axis. Additionally, the production of corticotrophin-releasing hormone (CRH) production is abnormal while pituitary and adrenal sensitivity seem to be intact [56] (figure 1). CRH is produced in the paraventricular nucleus of the hypothalamus in response to psychosocial stress and activates the HPA axis. It is binding in the pituitary gland to induce release of adrenocorticotropine hormone (ACTH), which in turn stimulates the release of cortisol from the adrenal gland. In a negative feedback loop, cortisol binding inhibits CRH and ACTH release, inhibiting the HPA axis [57], but this hormonal feedback is known to be abnormal in depression. In animal models, CRH administration and overexpression induce depressionlike behavior, while CRH antagonists have antidepressant properties [58, 59]. Depressed patients with history of childhood abuse have enhanced HPA axis response to psychosocial stress and attenuated adrenocorticotrophin and cortisol response to application of the synthetic corticosteroid dexamethasone [60]. However, individual genetic background influences the incidence of depression in response to psychosocial stress and only a minority of persons exposed to common stressors develops depression [61]. Thus, genes may modulate the association between environmental factors like stress and risk of illness.

\section{Genetic findings}

Twin, family and adoption studies have shown that major depression is a moderate heritable disease. During the last years, candidate gene and genome-wide association studies (GWAS) have linked common DNA sequence variation, called polymorphisms, to major depression [62-64] and identified novel candidate loci [65]. However, single nucleotide polymorphisms (SNPs) only slightly affect the pathophysiology, and affective disorders seem to be of complex polygenetic origin. With respect to CRH dysfunction, a genetic variation of the corticotropin releasing hormone type 1 receptor (CRHR1) has been found to be associated with decreased HPA axis response to CRH infusion, suggesting to influence this pathophysiology of depression [66]. In addition, negative feedback control on CRH secretion may be impaired due to altered glucocorticoid receptor (GR) function on hippocampal level [67]. A GR polymorphism has also been found to be associated with vulnerability to depression [68]. According to the neurotrophin hypothesis, in patients with depression and healthy controls, smaller hippocampal volumes have been detected in carriers of the BDNF Met66 allele compared to Val/Val homozygotes [69]. These results suggest that a Val66Met polymorphism may possibly predispose to smaller hippocampal volumes and depression, although this topic currently is under debate [70]. An interaction between a 5-HTTLPR serotonin transporter polymorphism and Val66Met BDNF gene 
variant has been shown to be associated to stress-induced depression [71-73]. Furthermore, depression has been associated with polymorphisms in the glucocorticoid receptor gene NR3C1, the monoamine oxidase A gene, and genes for glycogen synthase kinase-3B, a neuron-specific neutral amino acid transporter (SLC6A15) as well as group-2 metabotropic glutamate receptor (GRM3) [74, 75].

\section{Overactive Stress System in Depression}

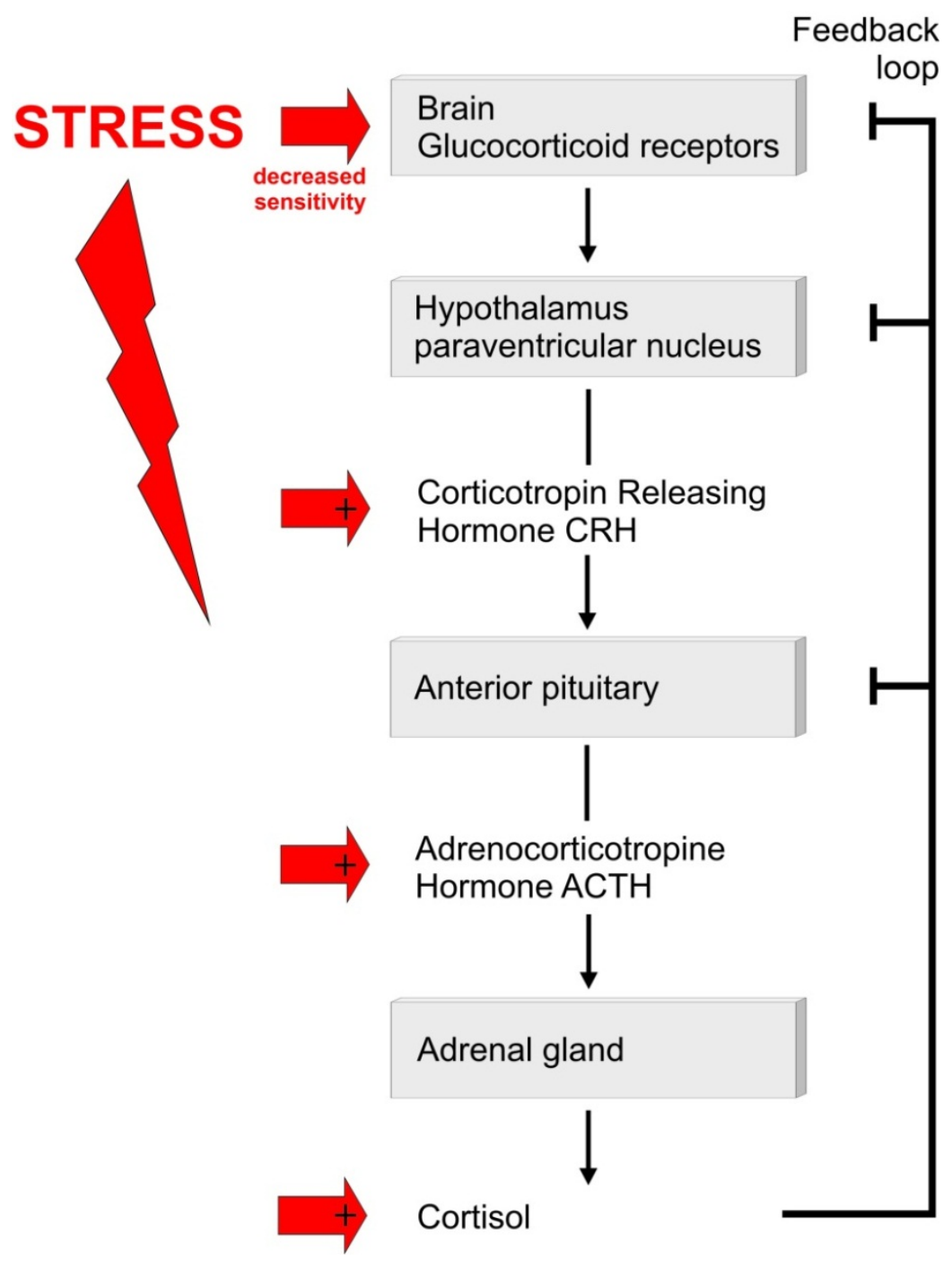

Figure 1. 
Several other genes are associated with bipolar disorder inclusive brain-derived neurotrophic factor (BDNF), D-amino acid oxidase activator (DAOA, G72), disrupted in schizophrenia 1 (DISC1), solute carrier family 6 (SLC6A4), tryptophan hydroxylase 2 (TPH2), catechol-O-methyltransferase (COMT), serotonin transporter (5-HTT) [76-81], but there is a large overlap with schizophrenia-associated genes, pointing to a continuum between affective disorders and psychosis. Among the risk variants for bipolar disorder, to date G72 is the most supported locus [76, 82-84]. However, there is also evidence for an association with depression and panic disorder [78, 85]. Additionally, G72 possibly influences a predisposition for affective symptoms in schizophrenia [83]. A further risk gene for bipolar disorder and depression is diacylglycerol kinase (DGKH), showing 10 SNPs to be associated with bipolar disorder while 7 SNPs are associated with unipolar depression and four SNPs with ADHD, thus influencing mood instability [86]. Additionally, a region of both ankyrin 3 (ANK3) and neurocan (NCAN) has been found to be associated with bipolar disorder [65, 87]. A recent meta-analysis revealed association of two SNPs in the serotonin $1 \mathrm{~A}$ receptor gene with major depression and bipolar disorder and supports the hypothesis of disturbed serotonin neurotransmission in mood disorder [88].

Altogether, the heritability of major depression seems to be meager compared to bipolar disorder and schizophrenia, which show heritability rates of up to $80 \%$. To date, GWAS studies could not identify many reproducible individual gene loci associated with affective disorders [89], but SNPs near exons exhibit a greater probability of replication, supporting an enrichment of reproducible associations near functional regions of genes [90]. However, the confirmation of some loci affords larger samples. In a GWAS study from the GWAS consortium Bipolar Disorder Working Group, in large cohorts evidence for association of CACN1C, an L-type voltage-gated calcium channel has been confirmed [91]. In order to improve methodological quality, new investigations using next-generation sequencing are under way.

Epigenetic mechanisms altering chromatin structure such as histone acetylation and DNA methylation may link effects of environmental factors such as stress to transcriptional regulation of specific genes. Depression-like behavior and antidepressant action have been found to be regulated by epigenetic mechanisms [92]. Besides downregulation of BDNF transcripts, stress increased histone methylation at their corresponding promoters. The antidepressant imipramine reversed the decrease on the mRNA level and increased histone acetylation along with downregulation of histone deacetylase, suggesting an important role in histone remodeling in the pathophysiology and treatment of depression [93]. As a consequence, new treatment strategies influencing epigenetic targets could be developed.

\section{Neurotransmitter hypotheses}

Selective antidepressant treatment is known to act on the serotonergic and the noradrenergic system. Traditional long-term antidepressant treatment is known to induce increased levels of serotonin from the raphe nuclei [94]. The serotonin hypothesis of depression suggests that decreased serotonin activity increases vulnerability for depression 
[95]. The serotonin system originates from the dorsal and medial raphe nuclei in the brainstem infringing on limbic structures such as the hippocampus and amygdala [94]. Reducing serotonin synthesis induces depressive symptoms in healthy probands exposed to uncontrollable stress [96], and increased serotonin release in the hippocampus has been implicated in the mechanisms underlying coping with stress [97]. Serotonin (5-HT) receptors are represented by $5-\mathrm{HT}_{1}$ class receptors, being situated pre- and postsynaptically and inhibitory by reduction of adenylate cyclase activity. The 5- $\mathrm{HT}_{2}$ class excitatory receptors are located predominantly postsynaptically through activation of phospholipase C [94]. 5-HT1A receptors are known to mediate adaption to stress and these receptors located in the hippocampus could attenuate the emotional impact of aversive stimuli, inhibiting the consolidation of stressfull memories [97]. Additionally, 5- $\mathrm{HT}_{1 \mathrm{~A}}$ receptors are known to mediate the serotonin-based increase in neurogenesis [98] and induce release of neurotrophic factors [99]. Moreover, serotonin is involved in the regulation of the HPA axis [100]. The downregulation of 5-HT1A receptors in the hippocampus by stressors is corticoiddependent and reversed by antidepressants [101, 102]. Indeed, patients with depression have reduced 5-HTiA receptor binding as revealed by positron emission tomography (PET) studies $[103,104]$ plus results of altered receptor number in post-mortem investigations [105, 106].

The noradrenaline system derives from the locus coeruleus and lateral tegmental nuclei. The receptors belong to the excitatory postsynaptic $ß$-adrenergic, $\alpha_{1}$ and inhibitory pre- and postsynaptic $\alpha_{2}$ adrenergic categories. They have been shown to be upregulated in postmortem brains of patients with depression [95, 107], suggesting a primary noradrenaline deficit. Stressors and glucocorticoids persistently activate the noradrenergic system in the locus coeruleus with resulting disrupted responses to brief stimuli [94]. In contrast to the posterior hippocampus, facilitation of noradrenergic transmission in the ventral hippocampus, being involved in emotion and anxiety [108, 109], seems to protect against stress effects [110]. Moreover, the noradrenaline system closely interacts with serotonin, facilitating serotonin neurotransmission in the hippocampus and amygdala [97] thus providing a therapeutic target for antidepressant drugs such as noradrenaline reuptake inhibitors [111]. Dopamine is another monoamine proposed to play a role in mood disorder since the mesolimbic dopamine reward circuit originating from the ventral tegmental area is associated with rewarding effects of food, sex and drug abuse. A dopaminergic deficit may contribute to anhedonia reduced motivation and energy level in patients with depression and may represent a target for the development of new therapeutic strategies [112]. It is expected that reuptake inhibitors for all three catecholamines (serotonin, noradrenaline, dopamine) can produce greater efficacy than traditional antidepressants [113].

It has been shown that 5-HT depletion alone does not induce mood symptoms, but an interaction with glutamate may be responsible for developing affective disorders. Additionally, noradrenaline is involved in release and uptake of glutamate [114]. Glutamate is the principal excitatory, $\gamma$-aminobutyric acid (GABA) the predominant inhibitory neurotransmitter in the brain, both occupying at least $50 \%$ of the synapses. Besides regulating synaptic plasticity, they closely interact with the HPA axis. In depression, an 
overactive glutamate system and hypoactive GABA system has been suggested [115]. Elevated levels of glutamine/glutamate have been shown in MR-spectroscopy (MRS) studies in the frontal and occipital cortex as well as in basal ganglia of patients with depression. In the anterior cingulate cortex, reduced levels have been reported in depression, while in bipolar disorder with acute mania, glutamate/glutamine levels were increased [28]. These findings are consistent with glutamatergic overactivity in acute mania. However, medication effects may contribute to the findings in mood disorder. In medication-free depressed patients, GABA levels have been found to be reduced in the occipital and anterior cingulate cortex as well as prefrontal cortex [115]. In clinical studies, agonists at the glycine site of the glutamatergic N-methyl-D-aspartate (NMDA) receptor as well as inhibitors of the glycine transporter elevating glycine levels have been found to exert antidepressant properties. But also antagonists at the NMDA receptor like ketamine induce a presynaptic release of glutamate, which in turn activates glutamatergic $\alpha$-amino-3-hydroxy-5-methylisoxazole-4-propionic acid (AMPA) receptors act as antidepressants [116-118]. Novel potential therapeutic drugs affecting the glutamate system are under investigation, such as modulators of AMPA receptors, NMDA receptor subunit NR2B, metabotropic glutamate receptors, glutamate transporter EAAT2, and N-acetyl-L-cysteine which is a precursor of the NMDA receptor activating antioxidant glutathione [117, 119].

\section{Findings on the molecular level}

The above described neurotransmitters are known to modulate gene transcription and protein synthesis [120]. Proteomic studies in the frontal cortex and nucleus accumbens of depressed patients revealed altered expression of Dihydropyrimidinase-related protein 2 (DPYSL2), regulating neuronal development, migration and differentiation as well as differential expression of aldolase C (ALDOC), which plays a major role in glucose and energy metabolism [121]. In the dorsolateral prefrontal cortex, proteomic profiles and a phosphoproteomic approach showed differences in proteins associated with synaptic transmission and cellular architecture [122] [123]. In bipolar disorder, dysregulation of DPYSL2 and glial fibrillary acid protein (GFAP) along with tubulin subunits suggest cytoskeletal dysfunction and altered brain development [121].

Genome-wide gene expression studies in bipolar disorder unearthed a high correlation of expression changes also observed in schizophrenia such as decreased oligodendrocyte and myelination related genes, as well as deregulation of mitochondrial energy metabolism, oxidative phosphorylation, synapse-related and mitochondrial genes [124, 125]. In depressed patients, alterations of genes involved in neurodevelopment, signal transduction, cell communication and myelination have been reported. Additionally, genes encoding for the glutamate and serotonin system have been found to be altered in bipolar disorder and depression [125]. Moreover, in mood disorder, alterations of BDNF and subunits of glutamate receptors and the GABA synthesizing enzyme GAD have been detected to be differentially regulated [126]. In a previous laser-capture microdissection study of the locus coeruleus, Bernard [127] found alterations of the glutamate-, astroglia- and growth factor 
related genes in depression, but not in bipolar disorder, suggesting differential processes in both disorders. In the frontal cortex of patients with major depression, increased apoptosis stress and upregulation of pro-and anti-inflammatory cytokines have been detected [128] which differs from findings in schizophrenia [129]. Interestingly, in an animal study, chronic stress affected expression of genes involved in brain development, morphogenesis and synaptic transmission in the dentate gyrus of the hippocampus, which is involved in neurogenesis [130]. Modulation of these stress effects may lead to development of new therapeutic strategies for mood disorder.

\section{Conclusion}

Overall, mood disorder entails a broad spectrum of alterations in specific neuronal circuits. Despite overlapping findings in patients with major depression, bipolar disorder and even schizophrenia, pointing to a neurobiological continuum of the diagnostic spectrum of psychoses, specific findings can be detected on the cellular, molecular and hormonal level. Besides genetics, environmental factors like acute or chronic stress are known to account for the pathophysiology of the named disorders. New treatment strategies involving several neurotransmitter systems are under way and may improve outcome. However, preventive and cause-related treatments based on molecular findings plus animal studies of environmental and genetic factors should be developed to increase efficacy and prevent burden of severe psychiatric diseases.

\section{Author details}

Peter Falkai and Andrea Schmitt

Department of Psychiatry and Psychotherapy, Ludwig-Maximilians-University Munich, Munich, Germany

Berend Malchow

Department of Psychiatry and Psychotherapy, Ludwig-Maximilians-University Munich, Munich, Germany

Department of Psychiatry and Psychotherapy, University of Göttingen, Göttingen, Germany

\section{References}

[1] Menken M, Munsat TL, Toole JF. The global burden of disease study: implications for neurology. Archives of neurology. 2000;57(3):418-20. Epub 2000/03/14.

[2] Kessler RC, Berglund P, Demler O, Jin R, Merikangas KR, Walters EE. Lifetime prevalence and age-of-onset distributions of DSM-IV disorders in the National Comorbidity Survey Replication. Arch Gen Psychiatry. 2005;62(6):593-602. Epub 2005/06/09.

[3] Evans DL, Charney DS, Lewis L, Golden RN, Gorman JM, Krishnan KR, et al. Mood disorders in the medically ill: scientific review and recommendations. Biol Psychiatry. 2005;58(3):175-89. Epub 2005/08/09. 
[4] Baldessarini RJ. Treatment research in bipolar disorder: issues and recommendations. CNS drugs. 2002;16(11):721-9. Epub 2002/10/18.

[5] Goldberg JF, Harrow M, Whiteside JE. Risk for bipolar illness in patients initially hospitalized for unipolar depression. Am J Psychiatry. 2001;158(8):1265-70. Epub 2001/08/02.

[6] Leweke FM, Giuffrida A, Wurster U, Emrich HM, Piomelli D. Elevated endogenous cannabinoids in schizophrenia. Neuroreport. 1999;10(8):1665-9. Epub 1999/09/29.

[7] Strakowski SM, Delbello MP, Adler CM. The functional neuroanatomy of bipolar disorder: a review of neuroimaging findings. Mol Psychiatry. 2005;10(1):105-16. Epub 2004/09/02.

[8] Ellison-Wright I, Bullmore E. Anatomy of bipolar disorder and schizophrenia: a metaanalysis. Schizophr Res. 2010;117(1):1-12. Epub 2010/01/15.

[9] De Peri L, Crescini A, Deste G, Fusar-Poli P, Sacchetti E, Vita A. Brain structural abnormalities at the onset of schizophrenia and bipolar disorder: a meta-analysis of controlled magnetic resonance imaging studies. Curr Pharm Des. 2012;18(4):486-94. Epub 2012/01/14.

[10] Gruber SA, Rogowska J, Yurgelun-Todd DA. Decreased activation of the anterior cingulate in bipolar patients: an fMRI study. J Affect Disord. 2004;82(2):191-201. Epub 2004/10/19.

[11] Lennox BR, Jacob R, Calder AJ, Lupson V, Bullmore ET. Behavioural and neurocognitive responses to sad facial affect are attenuated in patients with mania. Psychol Med. 2004;34(5):795-802. Epub 2004/10/27.

[12] Chen CH, Suckling J, Lennox BR, Ooi C, Bullmore ET. A quantitative meta-analysis of fMRI studies in bipolar disorder. Bipolar Disord. 2011;13(1):1-15. Epub 2011/02/16.

[13] Kupferschmidt DA, Zakzanis KK. Toward a functional neuroanatomical signature of bipolar disorder: quantitative evidence from the neuroimaging literature. Psychiatry Res. 2011;193(2):71-9. Epub 2011/06/17.

[14] Vederine FE, Wessa M, Leboyer M, Houenou J. A meta-analysis of whole-brain diffusion tensor imaging studies in bipolar disorder. Prog Neuropsychopharmacol Biol Psychiatry. 2011;35(8):1820-6. Epub 2011/06/01.

[15] Usher J, Leucht S, Falkai P, Scherk H. Correlation between amygdala volume and age in bipolar disorder - a systematic review and meta-analysis of structural MRI studies. Psychiatry Res. 2010;182(1):1-8. Epub 2010/03/17.

[16] Pfeifer JC, Welge J, Strakowski SM, Adler CM, DelBello MP. Meta-analysis of amygdala volumes in children and adolescents with bipolar disorder. J Am Acad Child Adolesc Psychiatry. 2008;47(11):1289-98. Epub 2008/10/02.

[17] Arnone D, McIntosh AM, Chandra P, Ebmeier KP. Meta-analysis of magnetic resonance imaging studies of the corpus callosum in bipolar disorder. Acta Psychiatr Scand. 2008;118(5):357-62. Epub 2008/07/23.

[18] Kempton MJ, Salvador Z, Munafo MR, Geddes JR, Simmons A, Frangou S, et al. Structural neuroimaging studies in major depressive disorder. Meta-analysis and comparison with bipolar disorder. Arch Gen Psychiatry. 2011;68(7):675-90. Epub 2011/07/06. 
[19] Arnone D, McIntosh AM, Ebmeier KP, Munafo MR, Anderson IM. Magnetic resonance imaging studies in unipolar depression: systematic review and meta-regression analyses. Eur Neuropsychopharmacol. 2012;22(1):1-16. Epub 2011/07/05.

[20] Cole J, Costafreda SG, McGuffin P, Fu CH. Hippocampal atrophy in first episode depression: a meta-analysis of magnetic resonance imaging studies. J Affect Disord. 2011;134(1-3):483-7. Epub 2011/07/13.

[21] Cole J, Toga AW, Hojatkashani C, Thompson P, Costafreda SG, Cleare AJ, et al. Subregional hippocampal deformations in major depressive disorder. J Affect Disord. 2010;126(1-2):272-7. Epub 2010/04/16.

[22] McEwen BS, Magarinos AM. Stress and hippocampal plasticity: implications for the pathophysiology of affective disorders. Hum Psychopharmacol. 2001;16(S1):S7-S19. Epub 2002/10/31.

[23] Fanselow MS. Contextual fear, gestalt memories, and the hippocampus. Behav Brain Res. 2000;110(1-2):73-81. Epub 2000/05/10.

[24] Knable MB, Barci BM, Webster MJ, Meador-Woodruff J, Torrey EF. Molecular abnormalities of the hippocampus in severe psychiatric illness: postmortem findings from the Stanley Neuropathology Consortium. Mol Psychiatry. 2004;9(6):609-20, 544. Epub 2004/01/07.

[25] Rosoklija G, Toomayan G, Ellis SP, Keilp J, Mann JJ, Latov N, et al. Structural abnormalities of subicular dendrites in subjects with schizophrenia and mood disorders: preliminary findings. Arch Gen Psychiatry. 2000;57(4):349-56. Epub 2000/04/18.

[26] Stockmeier CA, Mahajan GJ, Konick LC, Overholser JC, Jurjus GJ, Meltzer HY, et al. Cellular changes in the postmortem hippocampus in major depression. Biol Psychiatry. 2004;56(9):640-50. Epub 2004/11/04.

[27] Rajkowska G, Miguel-Hidalgo JJ, Wei J, Dilley G, Pittman SD, Meltzer HY, et al. Morphometric evidence for neuronal and glial prefrontal cell pathology in major depression. Biol Psychiatry. 1999;45(9):1085-98. Epub 1999/05/20.

[28] Ongur D, Jensen JE, Prescot AP, Stork C, Lundy M, Cohen BM, et al. Abnormal glutamatergic neurotransmission and neuronal-glial interactions in acute mania. Biol Psychiatry. 2008;64(8):718-26. Epub 2008/07/08.

[29] Cotter D, Mackay D, Landau S, Kerwin R, Everall I. Reduced glial cell density and neuronal size in the anterior cingulate cortex in major depressive disorder. Arch Gen Psychiatry. 2001;58(6):545-53. Epub 2001/06/29.

[30] Bowley MP, Drevets WC, Ongur D, Price JL. Low glial numbers in the amygdala in major depressive disorder. Biol Psychiatry. 2002;52(5):404-12. Epub 2002/09/21.

[31] Watanabe Y, Gould E, Cameron HA, Daniels DC, McEwen BS. Phenytoin prevents stress- and corticosterone-induced atrophy of CA3 pyramidal neurons. Hippocampus. 1992;2(4):431-5. Epub 1992/10/01.

[32] Sapolsky RM, Uno H, Rebert CS, Finch CE. Hippocampal damage associated with prolonged glucocorticoid exposure in primates. J Neurosci. 1990;10(9):2897-902. Epub 1990/09/01. 
[33] Rajkowska G. Postmortem studies in mood disorders indicate altered numbers of neurons and glial cells. Biol Psychiatry. 2000;48(8):766-77. Epub 2000/11/07.

[34] Arango C, Kirkpatrick B, Koenig J. At issue: stress, hippocampal neuronal turnover, and neuropsychiatric disorders. Schizophr Bull. 2001;27(3):477-80. Epub 2001/10/13.

[35] Frodl T, O'Keane V. How does the brain deal with cumulative stress? A review with focus on developmental stress, HPA axis function and hippocampal structure in humans. Neurobiol Dis. 2012. Epub 2012/03/20.

[36] Cameron HA, McKay RD. Restoring production of hippocampal neurons in old age. Nat Neurosci. 1999;2(10):894-7. Epub 1999/09/24.

[37] Cameron HA, Tanapat P, Gould E. Adrenal steroids and N-methyl-D-aspartate receptor activation regulate neurogenesis in the dentate gyrus of adult rats through a common pathway. Neuroscience. 1998;82(2):349-54. Epub 1998/02/18.

[38] Rayen I, van den Hove DL, Prickaerts J, Steinbusch HW, Pawluski JL. Fluoxetine during development reverses the effects of prenatal stress on depressive-like behavior and hippocampal neurogenesis in adolescence. PloS one. 2011;6(9):e24003. Epub 2011/09/14.

[39] Gould E, McEwen BS, Tanapat P, Galea LA, Fuchs E. Neurogenesis in the dentate gyrus of the adult tree shrew is regulated by psychosocial stress and NMDA receptor activation. J Neurosci. 1997;17(7):2492-8. Epub 1997/04/01.

[40] Gould E, Tanapat P. Stress and hippocampal neurogenesis. Biol Psychiatry. 1999;46(11):1472-9. Epub 1999/12/22.

[41] Tanapat P, Galea LA, Gould E. Stress inhibits the proliferation of granule cell precursors in the developing dentate gyrus. International journal of developmental neuroscience : the official journal of the International Society for Developmental Neuroscience. 1998;16(3-4):235-9. Epub 1998/10/24.

[42] Duman RS. Depression: a case of neuronal life and death? Biol Psychiatry. 2004;56(3):140-5. Epub 2004/07/24.

[43] Krugers HJ, Koolhaas JM, Bohus B, Korf J. A single social stress-experience alters glutamate receptor-binding in rat hippocampal CA3 area. Neurosci Lett. 1993;154(12):73-7. Epub 1993/05/14.

[44] Moghaddam B, Bolinao ML, Stein-Behrens B, Sapolsky R. Glucocorticoids mediate the stress-induced extracellular accumulation of glutamate. Brain Res. 1994;655(1-2):251-4. Epub 1994/08/29.

[45] Czeh B, Welt T, Fischer AK, Erhardt A, Schmitt W, Muller MB, et al. Chronic psychosocial stress and concomitant repetitive transcranial magnetic stimulation: effects on stress hormone levels and adult hippocampal neurogenesis. Biol Psychiatry. 2002;52(11):1057-65. Epub 2002/12/04.

[46] Malberg JE, Duman RS. Cell proliferation in adult hippocampus is decreased by inescapable stress: reversal by fluoxetine treatment. Neuropsychopharmacology. 2003;28(9):1562-71. Epub 2003/07/03.

[47] Manev H, Uz T, Smalheiser NR, Manev R. Antidepressants alter cell proliferation in the adult brain in vivo and in neural cultures in vitro. European journal of pharmacology. 2001;411(1-2):67-70. Epub 2001/01/04. 
[48] Coyle JT, Duman RS. Finding the intracellular signaling pathways affected by mood disorder treatments. Neuron. 2003;38(2):157-60. Epub 2003/04/30.

[49] Encinas JM, Vaahtokari A, Enikolopov G. Fluoxetine targets early progenitor cells in the adult brain. Proc Natl Acad Sci U S A. 2006;103(21):8233-8. Epub 2006/05/17.

[50] Zigova T, Pencea V, Betarbet R, Wiegand SJ, Alexander C, Bakay RA, et al. Neuronal progenitor cells of the neonatal subventricular zone differentiate and disperse following transplantation into the adult rat striatum. Cell transplantation. 1998;7(2):137-56. Epub 1998/05/20.

[51] Dunham JS, Deakin JF, Miyajima F, Payton A, Toro CT. Expression of hippocampal brain-derived neurotrophic factor and its receptors in Stanley consortium brains. J Psychiatr Res. 2009;43(14):1175-84. Epub 2009/04/21.

[52] Neto FL, Borges G, Torres-Sanchez S, Mico JA, Berrocoso E. Neurotrophins role in depression neurobiology: a review of basic and clinical evidence. Current neuropharmacology. 2011;9(4):530-52. Epub 2012/06/02.

[53] Brunoni AR, Lopes M, Fregni F. A systematic review and meta-analysis of clinical studies on major depression and BDNF levels: implications for the role of neuroplasticity in depression. Int J Neuropsychopharmacol. 2008;11(8):1169-80. Epub 2008/08/30.

[54] Gorgulu Y, Caliyurt O. Rapid antidepressant effects of sleep deprivation therapy correlates with serum BDNF changes in major depression. Brain research bulletin. 2009;80(3):158-62. Epub 2009/07/07.

[55] Magarinos AM, Li CJ, Gal Toth J, Bath KG, Jing D, Lee FS, et al. Effect of brain-derived neurotrophic factor haploinsufficiency on stress-induced remodeling of hippocampal neurons. Hippocampus. 2011;21(3):253-64. Epub 2010/01/23.

[56] Palazidou E. The neurobiology of depression. Br Med Bull. 2012;101:127-45. Epub 2012/02/16.

[57] Bogdan R, Nikolova YS, Pizzagalli DA. Neurogenetics of depression: A focus on reward processing and stress sensitivity. Neurobiol Dis. 2012. Epub 2012/06/05.

[58] Hauger RL, Risbrough V, Brauns O, Dautzenberg FM. Corticotropin releasing factor (CRF) receptor signaling in the central nervous system: new molecular targets. CNS \& neurological disorders drug targets. 2006;5(4):453-79. Epub 2006/08/22.

[59] Zieba B, Grzegorzewska M, Branski P, Domin H, Wieronska JM, Hess G, et al. The behavioural and electrophysiological effects of CRF in rat frontal cortex. Neuropeptides. 2008;42(5-6):513-23. Epub 2008/07/12.

[60] Heim C, Newport DJ, Heit S, Graham YP, Wilcox M, Bonsall R, et al. Pituitary-adrenal and autonomic responses to stress in women after sexual and physical abuse in childhood. Jama. 2000;284(5):592-7. Epub 2000/08/05.

[61] Keers R, Uher R. Gene-environment interaction in major depression and antidepressant treatment response. Current psychiatry reports. 2012;14(2):129-37. Epub 2011/12/27.

[62] Caspi A, Sugden K, Moffitt TE, Taylor A, Craig IW, Harrington H, et al. Influence of life stress on depression: moderation by a polymorphism in the 5-HTT gene. Science. 2003;301(5631):386-9. Epub 2003/07/19. 
[63] Levinson DF. The genetics of depression: a review. Biol Psychiatry. 2006;60(2):84-92. Epub 2005/11/23.

[64] Sullivan PF, de Geus EJ, Willemsen G, James MR, Smit JH, Zandbelt T, et al. Genomewide association for major depressive disorder: a possible role for the presynaptic protein piccolo. Mol Psychiatry. 2009;14(4):359-75. Epub 2008/12/10.

[65] Cichon S, Muhleisen TW, Degenhardt FA, Mattheisen M, Miro X, Strohmaier J, et al. Genome-wide association study identifies genetic variation in neurocan as a susceptibility factor for bipolar disorder. American journal of human genetics. 2011;88(3):372-81. Epub 2011/03/01.

[66] Ressler KJ, Bradley B, Mercer KB, Deveau TC, Smith AK, Gillespie CF, et al. Polymorphisms in CRHR1 and the serotonin transporter loci: gene $x$ gene $x$ environment interactions on depressive symptoms. Am J Med Genet B Neuropsychiatr Genet. 2010;153B(3):812-24. Epub 2009/12/24.

[67] Claes S. Glucocorticoid receptor polymorphisms in major depression. Ann N Y Acad Sci. 2009;1179:216-28. Epub 2009/11/13.

[68] Lahti J, Raikkonen K, Bruce S, Heinonen K, Pesonen AK, Rautanen A, et al. Glucocorticoid receptor gene haplotype predicts increased risk of hospital admission for depressive disorders in the Helsinki birth cohort study. J Psychiatr Res. 2011;45(9):1160-4. Epub 2011/04/12.

[69] Frodl T, Schule C, Schmitt G, Born C, Baghai T, Zill P, et al. Association of the brainderived neurotrophic factor Val66Met polymorphism with reduced hippocampal volumes in major depression. Arch Gen Psychiatry. 2007;64(4):410-6. Epub 2007/04/04.

[70] Yulug B, Ozan E, Kilic E. Brain-derived neurotrophic factor polymorphism as a genetic risk for depression? A short review of the literature. J Neuropsychiatry Clin Neurosci. 2010;22(1):123 E5-6. Epub 2010/02/18.

[71] Aguilera M, Arias B, Wichers M, Barrantes-Vidal N, Moya J, Villa H, et al. Early adversity and 5-HTT/BDNF genes: new evidence of gene-environment interactions on depressive symptoms in a general population. Psychol Med. 2009;39(9):1425-32. Epub 2009/02/14.

[72] Wichers M, Kenis G, Jacobs N, Mengelers R, Derom C, Vlietinck R, et al. The BDNF $\operatorname{Val}(66)$ Met $x$ 5-HTTLPR $\times$ child adversity interaction and depressive symptoms: An attempt at replication. Am J Med Genet B Neuropsychiatr Genet. 2008;147B(1):120-3. Epub 2007/06/21.

[73] Golimbet V, Alfimova M, Korovaitseva G, Abramova LI, Kaled VG. Emotional distress in parents of psychotic patients is modified by serotonin transporter gene (5-HTTLPR)-brain-derived neurotrophic factor gene interactions. The Spanish journal of psychology. 2009;12(2):696-706. Epub 2009/11/11.

[74] Kohli MA, Lucae S, Saemann PG, Schmidt MV, Demirkan A, Hek K, et al. The neuronal transporter gene SLC6A15 confers risk to major depression. Neuron. 2011;70(2):252-65. Epub 2011/04/28.

[75] Kupfer DJ, Frank E, Phillips ML. Major depressive disorder: new clinical, neurobiological, and treatment perspectives. Lancet. 2012;379(9820):1045-55. Epub 2011/12/23. 
[76] Schumacher J, Jamra RA, Freudenberg J, Becker T, Ohlraun S, Otte AC, et al. Examination of G72 and D-amino-acid oxidase as genetic risk factors for schizophrenia and bipolar affective disorder. Mol Psychiatry. 2004;9(2):203-7. Epub 2004/02/18.

[77] Maier W, Hofgen B, Zobel A, Rietschel M. Genetic models of schizophrenia and bipolar disorder: overlapping inheritance or discrete genotypes? Eur Arch Psychiatry Clin Neurosci. 2005;255(3):159-66. Epub 2005/07/05.

[78] Rietschel M, Beckmann L, Strohmaier J, Georgi A, Karpushova A, Schirmbeck F, et al. G72 and its association with major depression and neuroticism in large populationbased groups from Germany. Am J Psychiatry. 2008;165(6):753-62. Epub 2008/03/19.

[79] Barnett JH, Smoller JW. The genetics of bipolar disorder. Neuroscience. 2009;164(1):33143. Epub 2009/04/11.

[80] Dutt A, McDonald C, Dempster E, Prata D, Shaikh M, Williams I, et al. The effect of COMT, BDNF, 5-HTT, NRG1 and DTNBP1 genes on hippocampal and lateral ventricular volume in psychosis. Psychol Med. 2009;39(11):1783-97. Epub 2009/07/04.

[81] Purcell SM, Wray NR, Stone JL, Visscher PM, O'Donovan MC, Sullivan PF, et al. Common polygenic variation contributes to risk of schizophrenia and bipolar disorder. Nature. 2009;460(7256):748-52. Epub 2009/07/03.

[82] Fallin MD, Lasseter VK, Avramopoulos D, Nicodemus KK, Wolyniec PS, McGrath JA, et al. Bipolar I disorder and schizophrenia: a 440-single-nucleotide polymorphism screen of 64 candidate genes among Ashkenazi Jewish case-parent trios. American journal of human genetics. 2005;77(6):918-36. Epub 2005/12/29.

[83] Williams NM, Green EK, Macgregor S, Dwyer S, Norton N, Williams H, et al. Variation at the DAOA/G30 locus influences susceptibility to major mood episodes but not psychosis in schizophrenia and bipolar disorder. Arch Gen Psychiatry. 2006;63(4):36673. Epub 2006/04/06.

[84] Prata D, Breen G, Osborne S, Munro J, St Clair D, Collier D. Association of DAO and G72(DAOA)/G30 genes with bipolar affective disorder. Am J Med Genet B Neuropsychiatr Genet. 2008;147B(6):914-7. Epub 2008/01/01.

[85] Schumacher J, Abou Jamra R, Becker T, Klopp N, Franke P, Jacob C, et al. Investigation of the DAOA/G30 locus in panic disorder. Mol Psychiatry. 2005;10(5):428-9. Epub 2004/10/13.

[86] Weber H, Kittel-Schneider S, Gessner A, Domschke K, Neuner M, Jacob CP, et al. Crossdisorder analysis of bipolar risk genes: further evidence of DGKH as a risk gene for bipolar disorder, but also unipolar depression and adult ADHD. Neuropsychopharmacology. 2011;36(10):2076-85. Epub 2011/06/10.

[87] Ferreira MA, O'Donovan MC, Meng YA, Jones IR, Ruderfer DM, Jones L, et al. Collaborative genome-wide association analysis supports a role for ANK3 and CACNA1C in bipolar disorder. Nature genetics. 2008;40(9):1056-8. Epub 2008/08/20.

[88] Kishi T, Yoshimura R, Fukuo Y, Okochi T, Matsunaga S, Umene-Nakano W, et al. The serotonin $1 \mathrm{~A}$ receptor gene confer susceptibility to mood disorders: results from an extended meta-analysis of patients with major depression and bipolar disorder. Eur Arch Psychiatry Clin Neurosci. 2012. Epub 2012/07/04. 
[89] Scott LJ, Muglia P, Kong XQ, Guan W, Flickinger M, Upmanyu R, et al. Genome-wide association and meta-analysis of bipolar disorder in individuals of European ancestry. Proc Natl Acad Sci U S A. 2009;106(18):7501-6. Epub 2009/05/07.

[90] Smith EN, Koller DL, Panganiban C, Szelinger S, Zhang P, Badner JA, et al. Genomewide association of bipolar disorder suggests an enrichment of replicable associations in regions near genes. PLoS genetics. 2011;7(6):e1002134. Epub 2011/07/09.

[91] Sklar P, Ripke S, Scott LJ, Andreassen OA, Cichon S, Craddock N, et al. Large-scale genome-wide association analysis of bipolar disorder identifies a new susceptibility locus near ODZ4. Nature genetics. 2011;43(10):977-83. Epub 2011/09/20.

[92] Sun H, Kennedy PJ, Nestler EJ. Epigenetics of the Depressed Brain: Role of Histone Acetylation and Methylation. Neuropsychopharmacology. 2012. Epub 2012/06/14.

[93] Tsankova NM, Berton O, Renthal W, Kumar A, Neve RL, Nestler EJ. Sustained hippocampal chromatin regulation in a mouse model of depression and antidepressant action. Nat Neurosci. 2006;9(4):519-25. Epub 2006/02/28.

[94] Ressler KJ, Nemeroff CB. Role of serotonergic and noradrenergic systems in the pathophysiology of depression and anxiety disorders. Depress Anxiety. 2000;12 Suppl 1:2-19. Epub 2000/12/01.

[95] Mann JJ. Role of the serotonergic system in the pathogenesis of major depression and suicidal behavior. Neuropsychopharmacology. 1999;21(2 Suppl):99S-105S. Epub 1999/08/05.

[96] Richell RA, Deakin JF, Anderson IM. Effect of acute tryptophan depletion on the response to controllable and uncontrollable noise stress. Biol Psychiatry. 2005;57(3):295300. Epub 2005/02/05.

[97] Joca SR, Ferreira FR, Guimaraes FS. Modulation of stress consequences by hippocampal monoaminergic, glutamatergic and nitrergic neurotransmitter systems. Stress. 2007;10(3):227-49. Epub 2007/07/07.

[98] Banasr M, Hery M, Printemps R, Daszuta A. Serotonin-induced increases in adult cell proliferation and neurogenesis are mediated through different and common 5-HT receptor subtypes in the dentate gyrus and the subventricular zone. Neuropsychopharmacology. 2004;29(3):450-60. Epub 2004/02/12.

[99] Galter D, Unsicker K. Sequential activation of the 5-HT1(A) serotonin receptor and TrkB induces the serotonergic neuronal phenotype. Molecular and cellular neurosciences. 2000;15(5):446-55. Epub 2000/06/02.

[100] Feldman S, Weidenfeld J. Glucocorticoid receptor antagonists in the hippocampus modify the negative feedback following neural stimuli. Brain Res. 1999;821(1):33-7. Epub 1999/03/05.

[101] Neumaier JF, Sexton TJ, Hamblin MW, Beck SG. Corticosteroids regulate 5-HT(1A) but not $5-\mathrm{HT}(1 \mathrm{~B})$ receptor mRNA in rat hippocampus. Brain research Molecular brain research. 2000;82(1-2):65-73. Epub 2000/10/24.

[102] Bijak M, Zahorodna A, Tokarski K. Opposite effects of antidepressants and corticosterone on the sensitivity of hippocampal CA1 neurons to 5-HT1A and 5-HT4 receptor activation. Naunyn-Schmiedeberg's archives of pharmacology. 2001;363(5):4918. Epub 2001/06/01. 
[103] Drevets WC, Frank E, Price JC, Kupfer DJ, Greer PJ, Mathis C. Serotonin type-1A receptor imaging in depression. Nuclear medicine and biology. 2000;27(5):499-507. Epub 2000/08/30.

[104] Sargent PA, Kjaer KH, Bench CJ, Rabiner EA, Messa C, Meyer J, et al. Brain serotonin1A receptor binding measured by positron emission tomography with [11C]WAY-100635: effects of depression and antidepressant treatment. Arch Gen Psychiatry. 2000;57(2):174-80. Epub 2000/02/09.

[105] Cheetham SC, Crompton MR, Katona CL, Horton RW. Brain 5-HT1 binding sites in depressed suicides. Psychopharmacology (Berl). 1990;102(4):544-8. Epub 1990/01/01.

[106] Stockmeier CA, Shapiro LA, Dilley GE, Kolli TN, Friedman L, Rajkowska G. Increase in serotonin-1A autoreceptors in the midbrain of suicide victims with major depressionpostmortem evidence for decreased serotonin activity. J Neurosci. 1998;18(18):7394-401. Epub 1998/09/16.

[107] Meana JJ, Barturen F, Garcia-Sevilla JA. Alpha 2-adrenoceptors in the brain of suicide victims: increased receptor density associated with major depression. Biol Psychiatry. 1992;31(5):471-90. Epub 1992/03/01.

[108] Bannerman DM, Rawlins JN, McHugh SB, Deacon RM, Yee BK, Bast T, et al. Regional dissociations within the hippocampus--memory and anxiety. Neurosci Biobehav Rev. 2004;28(3):273-83. Epub 2004/07/01.

[109] Bertoglio LJ, Joca SR, Guimaraes FS. Further evidence that anxiety and memory are regionally dissociated within the hippocampus. Behav Brain Res. 2006;175(1):183-8. Epub 2006/09/26.

[110] Petty F, Sherman AD. Regional aspects of the prevention of learned helplessness by desipramine. Life sciences. 1980;26(17):1447-52. Epub 1980/04/28.

[111] Dell'Osso B, Palazzo MC, Oldani L, Altamura AC. The noradrenergic action in antidepressant treatments: pharmacological and clinical aspects. CNS Neurosci Ther. 2011;17(6):723-32. Epub 2010/12/16.

[112] Nestler EJ, Carlezon WA, Jr. The mesolimbic dopamine reward circuit in depression. Biol Psychiatry. 2006;59(12):1151-9. Epub 2006/03/29.

[113] Prins J, Olivier B, Korte SM. Triple reuptake inhibitors for treating subtypes of major depressive disorder: the monoamine hypothesis revisited. Expert opinion on investigational drugs. 2011;20(8):1107-30. Epub 2011/06/21.

[114] Drago A, Crisafulli C, Sidoti A, Serretti A. The molecular interaction between the glutamatergic, noradrenergic, dopaminergic and serotoninergic systems informs a detailed genetic perspective on depressive phenotypes. Prog Neurobiol. 2011;94(4):41860. Epub 2011/07/05.

[115] Gao SF, Bao AM. Corticotropin-releasing hormone, glutamate, and gammaaminobutyric acid in depression. The Neuroscientist : a review journal bringing neurobiology, neurology and psychiatry. 2011;17(1):124-44. Epub 2010/03/20.

[116] Maeng S, Zarate CA, Jr. The role of glutamate in mood disorders: results from the ketamine in major depression study and the presumed cellular mechanism underlying its antidepressant effects. Current psychiatry reports. 2007;9(6):467-74. Epub 2008/01/29. 
[117] Hashimoto K. Emerging role of glutamate in the pathophysiology of major depressive disorder. Brain Res Rev. 2009;61(2):105-23. Epub 2009/06/02.

[118] Kugaya A, Sanacora G. Beyond monoamines: glutamatergic function in mood disorders. CNS Spectr. 2005;10(10):808-19. Epub 2006/01/10.

[119] Skolnick P, Popik P, Trullas R. Glutamate-based antidepressants: 20 years on. Trends Pharmacol Sci. 2009;30(11):563-9. Epub 2009/10/20.

[120] Kalia M. Neurobiological basis of depression: an update. Metabolism: clinical and experimental. 2005;54(5 Suppl 1):24-7. Epub 2005/05/07.

[121] Martins-de-Souza D, Harris LW, Guest PC, Turck CW, Bahn S. The role of proteomics in depression research. Eur Arch Psychiatry Clin Neurosci. 2010;260(6):499-506. Epub 2009/12/10.

[122] Martins-de-Souza D. Comprehending depression through proteomics. Int J Neuropsychopharmacol. 2012:1-2. Epub 2012/06/22.

[123] Martins-de-Souza D, Guest PC, Vanattou-Saifoudine N, Rahmoune H, Bahn S. Phosphoproteomic differences in major depressive disorder postmortem brains indicate effects on synaptic function. Eur Arch Psychiatry Clin Neurosci. 2012. Epub 2012/02/22.

[124] Lopez de Lara C, Jaitovich-Groisman I, Cruceanu C, Mamdani F, Lebel V, Yerko V, et al. Implication of synapse-related genes in bipolar disorder by linkage and gene expression analyses. Int J Neuropsychopharmacol. 2010;13(10):1397-410. Epub 2010/07/30.

[125] Sequeira A, Turecki G. Genome wide gene expression studies in mood disorders. Omics : a journal of integrative biology. 2006;10(4):444-54. Epub 2007/01/20.

[126] Kim S, Webster MJ. The stanley neuropathology consortium integrative database: a novel, web-based tool for exploring neuropathological markers in psychiatric disorders and the biological processes associated with abnormalities of those markers. Neuropsychopharmacology. 2010;35(2):473-82. Epub 2009/10/16.

[127] Bernard R, Kerman IA, Thompson RC, Jones EG, Bunney WE, Barchas JD, et al. Altered expression of glutamate signaling, growth factor, and glia genes in the locus coeruleus of patients with major depression. Mol Psychiatry. 2011;16(6):634-46. Epub 2010/04/14.

[128] Shelton RC, Claiborne J, Sidoryk-Wegrzynowicz M, Reddy R, Aschner M, Lewis DA, et al. Altered expression of genes involved in inflammation and apoptosis in frontal cortex in major depression. Mol Psychiatry. 2011;16(7):751-62. Epub 2010/05/19.

[129] Schmitt A, Leonardi-Essmann F, Durrenberger PF, Parlapani E, Schneider-Axmann T, Spanagel R, et al. Regulation of immune-modulatory genes in left superior temporal cortex of schizophrenia patients: a genome-wide microarray study. World J Biol Psychiatry. 2011;12(3):201-15. Epub 2010/11/26.

[130] Datson NA, Speksnijder N, Mayer JL, Steenbergen PJ, Korobko O, Goeman J, et al. The transcriptional response to chronic stress and glucocorticoid receptor blockade in the hippocampal dentate gyrus. Hippocampus. 2012;22(2):359-71. Epub 2010/12/25. 